\title{
Influence of Hot Pressing Technological Parameters on Plywood Bending Properties
}

\begin{abstract}
Uldis Spulle, ${ }^{\mathrm{a}, *}$ Anete Meija, ${ }^{\mathrm{a}}$ Laimonis Kūliņš, ${ }^{\mathrm{a}}$ Evija Kopeika, ${ }^{\mathrm{b}}$ Kārlis H. Liepa, ${ }^{\mathrm{a}}$ Haralds Šillers, ${ }^{a}$ and Kaspars Zudrags ${ }^{c}$

Different types of wood are used to manufacture of various wood products. In direct production processes, additional resources such as energy, adhesives, labor, etc. are also used. In line with sustainable environmental policies, all resources must be used more rationally, while simultaneously increasing the efficiency of the direct production processes. This research examined whether it is possible to reduce energy and labor resources in the technological process of hot pressing of birch plywood (nominal thickness $9 \mathrm{~mm}$ ), by varying the holding time under pressure, pressure, and adhesive consumption. The Box-Behnken experimental design for a multifactor experiment was used to investigate the influence of technological parameters of plywood pressing. The highest strength in static bending both parallel and perpendicular to the plywood grain was achieved by pressing plywood with the following gluing parameters: highest pressing pressure, 3.2 MPa; minimal holding time under pressure, 9 minutes; and average phenol-formaldehyde adhesive consumption 150 grams per square meter.
\end{abstract}

Keywords: Birch veneers; Density; Static 3 point bending; Holding time under pressure; Pressure; Adhesive consumption

Contact information: a: Latvia University of Life Sciences and Technologies, Lielā iela 2, Jelgava, LV3001, Latvia; b: Riga Technical University, Kallku iela 1, Rīga, LV-1658, Latvia; c: JSC "Latvijas Finieris”, Bauskas iela 59, Rīga, LV-1004, Latvia; *Corresponding author: uldis.spulle@llu.lv

\section{INTRODUCTION}

The use of birch in the production of plywood is one of the most economically advantageous ways of using that wood. Plywood production is still developing, especially in the last decade. Latvian plywood manufacturers such as JSC "Latvijas Finieris", "STIGA RM" Ltd. and veneer manufacturer "AmberBirch" Ltd. have invested large financial resources in the development of the existing and future technologies of veneer and plywood production. Latvian plywood manufacturers rank the $4^{\text {th }}$ in the world in birch plywood exports after Russia, Finland, and Poland. Current sustainable development policies around the world focus on increasing the value of products using fewer resources and reducing costs and environmental impact, i.e., doing more using less without major reduction of the quality of the final product. This is often achieved by reducing the amount of raw materials, energy, and labor. Wood materials, adhesive consumption, time, energy, etc. are components that can reduce resource input by more efficient production. Rational use of resources helps achieve the goal of creating more value with fewer resources, as the amount of quality resources, including quality wood resources, also decreases.

Birch plywood is mostly used for interior applications such as building construction, design elements, etc., covered with different lamination films, but it can be used for outdoor conditions as well. The use of wood in construction in Europe has tripled 
its market share compared to 2010 levels, and plywood is increasingly being used in construction (Horizons - Vision 2030 for the European Forest-based Sector 2013). In order to use plywood as a structural material in load-bearing structures, the necessary mechanical properties must be ensured, which are determined by laboratory testing of plywood for bending, compression, tensile strength, etc. properties. These properties, however, depend on the properties of the raw material or the characteristics of the wood: tree species or density, moisture content, wood temperature, etc. (Shupe et al. 1997). They also depend on the characteristics of the final product: the direction of the veneer grain in the mutual position of the veneers, the total thickness of plywood and number of veneer layers in it, the thickness of the veneer in the adjacent layers, etc. (Lipinskis and Spulle 2011). However, the mechanical properties of plywood can also be influenced by direct production processes: peeling technology, type of veneer drying, type and amount of the adhesive used, pressing parameters, etc. (Baldwin 2016).

Plywood gluing is usually carried out at elevated temperatures and under pressure. The veneer layers, especially the outer ones, are compressed; the density of plywood depends on the density of its veneers, moisture content, and the total thickness of plywood. The density of plywood is at least $15 \%$ higher than the density of veneers (Spulle 2003). Thinner plywood, when subjected to pressure during the gluing process, will compress more than thicker plywood (Volynsky 2008). Therefore, plastic deformations for thin plywood are greater. As the thickness of the plywood increases, the loss in its thickness or the pressing degree during the pressing process decreases. The pressing degree of the plywood is also affected by the moisture content of the veneers; higher moisture content results in a higher pressing degree of the plywood. For thinner veneer, more moisture is obtained by the plywood pack, which increases the density of the plywood. Pressing increases the strength of the plywood only during the initial stage of its application. Later, at varying temperatures and air relative humidity, the veneer regains its initial thickness, and the density of the plywood decreases slightly (Spulle 2003).

Different types of adhesives are used to produce plywood, depending on the desired properties of the materials. To obtain a moisture-resistant plywood, phenolic formaldehyde (PF) resin adhesive is used in hot pressing. Unmodified urea-formaldehyde (UF) resin adhesive is used if the final products are intended to be used indoors due to the limited moisture resistance of the resin. The benefit of using UF resin is the possibility of applying cold gluing (Hogger et al. 2018). This requires less energy in the direct production processes, although it is more time consuming because unmodified UF resin adhesive requires much longer holding time than hot pressing. Taking into account the large amount of water in the adhesives, the moisture content of the veneers should be in the range of 4 to $6 \%$. When using PF resin adhesive, the technological parameters of pressing are in the following ranges: temperature from 115 to $140{ }^{\circ} \mathrm{C}$, pressing pressure for softwoods from 0.8 to $1.5 \mathrm{MPa}$, for hardwoods from 1.5 to $2.5 \mathrm{MPa}$, holding time under pressure 6 minutes, plus 1 minute and 6 seconds per millimeter of plywood thickness and adhesive consumption from 160 to $230 \mathrm{~g} / \mathrm{m}^{2}$ (Zeppenfeld and Grunwald 2005). The choice of pressing pressure depends on the density of the wood, moisture content, and other factors (Wang and Dai 2005). Adhesive application time, veneer moisture content, veneer temperature, pre-pressing time, the interaction between application time and moisture content, as well as adhesive consumption and moisture content also noticeably affect the quality of plywood adhesion according to EN 314-1 (2004) and EN 314-2 (1993) or tensileshear strength (Hogger et al. 2018). The main pressing parameters that affect the mechanical properties of plywood are the pressing temperature and pressure. The pressing 
temperature is chosen so that it is high enough to allow the adhesive to cure, but not higher than the one at which the adhesive layer collapses (Wang and Dai 2005). The highest tensile shear strength is obtained at low veneer moisture content, higher veneer temperature, longer holding time and higher adhesive consumption. The lowest tensile-shear strength is obtained at high veneer moisture content and low temperature (Hogger et al. 2018). In plywood production, it is possible to decrease the consumption of adhesive by up to $25 \%$ and decrease the pressing pressure by up to $22 \%$ by densifying the veneers before applying the adhesive (Bekhta and Marutzky 2007). Pre-densification of veneers noticeably increases the physical-mechanical properties of plywood. However, it should be taken into account that in the process of plywood gluing veneer densification or compaction also occurs, and it can affect the final thickness of the plywood. Due to various factors, it is not possible to produce plywood of the same size, so permissible deviations from the respective thickness have been determined. According to the requirements of the standard EN 315, the upper limit of thickness tolerance for seven veneer layer, $9 \mathrm{~mm}$ thick plywood, at a moisture content of $10 \pm 2 \%$, is $9.5 \mathrm{~mm}$, which is also specified in the FFIF handbook (2002) and JSC "Latvijas Finieris" plywood handbook (2020). The lowest limit of thickness tolerance of the plywood in both handbooks mentioned above is $8.8 \mathrm{~mm}$, which is stricter compared to the requirements of standard EN 315 (2000) is $8.3 \mathrm{~mm}$. All of the above mentioned must also be taken into account at the time of holding under pressure and post treatment sanding or calibrating the plywood and then gluing it with laminating films or covering materials.

Based on the information mentioned above, the goal of the study was to determine the optimal 7-layer - $9 \mathrm{~mm}$ thick birch plywood hot pressing technological parameters, considering the possibility of reducing the holding time under pressure, pressing pressure and adhesive consumption without reducing the strength properties, and also to predict the plywood properties according to the determined pressing technological parameters. Consequently, due to a more efficient use of resources and potential increase in the production of plywood we would be able to manufacture more predictable plywood products with regard to plywood properties.

\section{EXPERIMENTAL}

\section{Raw Material Characteristics}

The 7-layer (Fig. 1) or $9 \mathrm{~mm}$ thick plywood of class B peeled birch veneers without visual wood defects, not sorted by density, were produced by JSC "Latvijas Finieris" (Riga, Latvia). The veneer thickness was $1.5 \mathrm{~mm}$, with width and length of $590 \times 590 \mathrm{~mm}$. The laying-up of veneers in the plywood to each other had perpendicular grain direction in the adjacent layers (Fig. 1). The average moisture content of veneers before gluing was 4 to $6 \%$. The values of the variable pressing parameters were used as follows:

- $\quad$ pressing pressure $1.2 ; 2.2$ or $3.2 \mathrm{MPa}$;

- holding time under pressure $9 ; 13.5$ or 18 minutes;

- adhesive consumption $100 ; 150$ or $200 \mathrm{~g} / \mathrm{m}^{2}$.

Phenol-formaldehyde resin adhesive, produced by JSC "Latvijas Finieris" (Riga, Latvia) was used for gluing the plywood, which requires an elevated temperature to cure and was $135^{\circ} \mathrm{C}$ for all variants. 


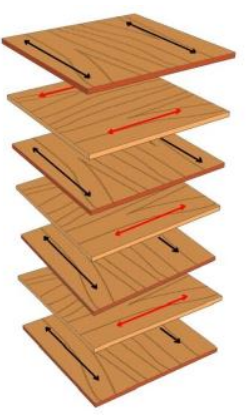

Fig. 1. Plywood laying-up scheme: $\leftrightarrow$ is direction of wood grain.

\section{Experimental Design Method}

Taking into account the fact that 3 parameters had to be investigated, each with 3 variants, the total number of experimental sample sets should be 27 . However, using the Box - Behnken experimental design method, the number of experimental variants can be reduced to 15. The experimental design is shown in Table 1. Experimental design matrices that depend on the number of variables. The variables and their markings in one type of experimental design matrix are given in Table 2.

Table 1. Rules of Experiment

\begin{tabular}{|c|c|c|c|c|c|c|}
\hline \multirow{2}{*}{$\begin{array}{l}\text { Designation } \\
\text { factors }\end{array}$} & \multirow{2}{*}{ Parameter } & \multirow{2}{*}{ Unit } & \multirow{2}{*}{ Variation interval $\Delta \mathrm{xi}_{\mathrm{i}}$} & \multicolumn{3}{|c|}{ Levels } \\
\hline & & & & -1 & 0 & +1 \\
\hline $\mathrm{X}_{1}$ & Pressure & $\mathrm{MPa}$ & 1 & 1.2 & 2.2 & 3.2 \\
\hline $\mathrm{X}_{2}$ & Time under pressure & minutes & 4.5 & 9 & 13.5 & 18 \\
\hline$x_{3}$ & $\begin{array}{l}\text { Adhesive } \\
\text { consumption }\end{array}$ & $\mathrm{g} / \mathrm{m}^{2}$ & 50 & 100 & 150 & 200 \\
\hline
\end{tabular}

Table 2. Research Parameters and Levels of the Experimental Planning Matrix

\begin{tabular}{|l|c|c|c|}
\hline \multirow{2}{*}{ Experiment No. } & \multicolumn{3}{|c|}{ Variables } \\
\cline { 2 - 4 } & $\begin{array}{l}\text { Pressure, MPa/ } \\
\text { designation }\end{array}$ & $\begin{array}{l}\text { Time under pressure, } \\
\text { minutes/ designation }\end{array}$ & $\begin{array}{l}\text { Adhesive consumption, } \mathrm{g} / \mathrm{m}^{2} / \\
\text { designation }\end{array}$ \\
\hline 1. & $3.2 / 1$ & $18 / 1$ & $150 / 0$ \\
\hline 2. & $3.2 / 1$ & $9 /-1$ & $150 / 0$ \\
\hline 3. & $1.2 /-1$ & $18 / 1$ & $150 / 0$ \\
\hline 4. & $1.2 /-1$ & $9 /-1$ & $150 / 0$ \\
\hline 5. & $3.2 / 1$ & $13.5 / 0$ & $200 / 1$ \\
\hline 6. & $3.2 / 1$ & $13.5 / 0$ & $100 /-1$ \\
\hline 7. & $1.2 /-1$ & $13.5 / 0$ & $200 / 1$ \\
\hline 8. & $1.2 /-1$ & $13.5 / 0$ & $100 /-1$ \\
\hline 9. & $2.2 / 0$ & $18 / 1$ & $200 / 1$ \\
\hline 10. & $2.2 / 0$ & $18 / 1$ & $100 /-1$ \\
\hline 11. & $2.2 / 0$ & $9 /-1$ & $200 / 1$ \\
\hline 12. & $2.2 / 0$ & $9 /-1$ & $100 /-1$ \\
\hline 13. & $2.2 / 0$ & $13.5 / 0$ & $150 / 0$ \\
\hline 14. & $2.2 / 0$ & $13.5 / 0$ & $150 / 0$ \\
\hline 15. & $2.2 / 0$ & $13.5 / 0$ & $150 / 0$ \\
\hline
\end{tabular}

After applying the adhesive, the total thickness of the veneers contained in one plywood piece was determined before pressing and immediately after their removal from the press. The obtained values were used to calculate the compression degree of plywood according to the Eq. 1, 


$$
C R=\frac{\left(T_{v}-T_{b}\right)}{T_{v}} \cdot 100
$$

where $C R$ is compression degree $(\%), T_{v}$ is thickness of the plywood before pressing $(\mathrm{mm})$, and $T_{b}$ is thickness of the plywood after pressing $(\mathrm{mm})$.

\section{Plywood Manufacturing and Samples}

The press JOOS LAP 150 (Gottfried Joos Maschinenfabrik GmbH \& Co. Pfalzgrafenweiler, Germany) with heated press plates was used for pressing plywood. The pressing surface dimensions were $600 \times 600 \mathrm{~mm}$. After gluing the plywood samples, they were placed in a conditioning chamber at constant environmental parameters (air temperature $20 \pm 3{ }^{\circ} \mathrm{C}$ and air relative humidity $65 \pm 5 \%$ ) until the samples obtained a constant mass. Then the preparation of samples was performed according to nominal dimensions: width $\times$ length $\times$ thickness $50 \times 230 \times 9 \mathrm{~mm}$ respectively. The samples were tested using the universal testing equipment Zwick Z100/TL3S (ZwickRoell, Ulm, Germany). The loading speed was chosen so that the sample collapse, in accordance with the requirements of standard EN 310 (1993), takes place within $60 \pm 30 \mathrm{~s}$. The empirical data of the sample groups obtained were compared using a $t$-test to check whether the average values obtained were significantly different. Data analysis was performed using multifactor linear logarithmic regression models and a heterosked problem test with Goldfeld-Quantand test and autocorrelation test with Durbin-Watson method were developed for all the obtained models. MS Excel and SPSS Statistic20 computer programs were used to process the empirical data obtained in the study.

\section{RESULTS}

\section{Bending Strength and Pressing Parameters}

When calculating the optimal pressing parameters in order to obtain the optimal static bending strength values - parallel to the grain, it was determined that the pressing pressure should be $1.9 \mathrm{MPa}$; the holding time under pressure must be 12 minutes and 36 seconds and the adhesive consumption should be $301 \mathrm{~g} / \mathrm{m}^{2}$. Concluding that the determined optimal adhesive consumption is higher than the upper limit of the variation set at 200 $\mathrm{g} / \mathrm{m}^{2}$, the optimal technological values have been recalculated: the pressing pressure must be $1.7 \mathrm{MPa}$ and the holding time under pressure 14 minutes and $48 \mathrm{~s}$. When determining the optimal pressing parameters to obtain the optimal value of the modulus of elasticity of bending in parallel with the fibers, it was determined that the pressing pressure should be 1.6 $\mathrm{MPa}$; holding time under pressure 12 minutes and $12 \mathrm{~s}$ and for adhesive consumption $140 \mathrm{~g} / \mathrm{m}^{2}$. It was concluded that all the obtained optimal values were within the range of variation, and no additional recalculation had to be performed. Figure 2 shows the strength values obtained in the static bending parallel to the grain.

The highest static bending strength was $111.5 \mathrm{~N} / \mathrm{mm}^{2}$, which was for the pressing technological variant with the following gluing parameters: pressing pressure $3.2 \mathrm{MPa}$, holding time under pressure 13.5 minutes, and adhesive consumption $200 \mathrm{~g} / \mathrm{m}^{2}$. The lowest static bending strength was $81.7 \mathrm{~N} / \mathrm{mm}^{2}$, which was the eighth variant with the following bonding parameters: pressing pressure 1.2 $\mathrm{MPa}$, average holding time under pressure 13.5 minutes, and the lowest adhesive consumption $100 \mathrm{~g} / \mathrm{m}^{2}$. For the three groups of samples, which all had the same pressing parameters of pressing pressure $2.2 \mathrm{MPa}$, holding time under pressure 13.5 minutes, and adhesive consumption $150 \mathrm{~g} / \mathrm{m}^{2}$, the lowest strength in 
static bending $86.8 \mathrm{~N} / \mathrm{mm}^{2}$ was obtained, and the highest $97.1 \mathrm{~N} / \mathrm{mm}^{2}$. The difference between these groups of samples was $10.3 \mathrm{~N} / \mathrm{mm}^{2}$. Using the t-test, differences in the variation of several unrelated sample sets were determined, and it was found that there were no significant differences between the sample sets. The observed difference between the sample averages was not conclusive enough to suggest that the average bending strength of these three plywood bonding groups would differ significantly. Figure 3 shows the strength values obtained in static bending perpendicular to the grain. The highest static bending strength of $73.7 \mathrm{~N} / \mathrm{mm}^{2}$ was for the technological solution with the following bonding parameters: pressing pressure $3.2 \mathrm{MPa}$, holding time under pressure 13.5 minutes and adhesive consumption $200 \mathrm{~g} / \mathrm{m}^{2}$.

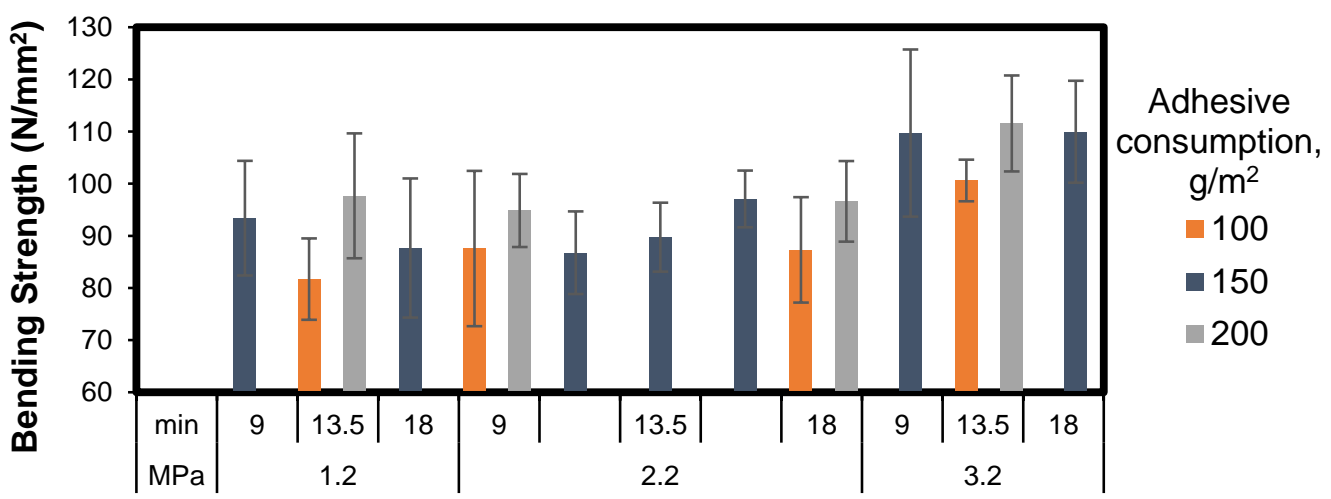

Time of Pressing (minutes) at the Pressure (MPa)

Fig. 2. Bending strength parallel to the grain (STDEV error bars)

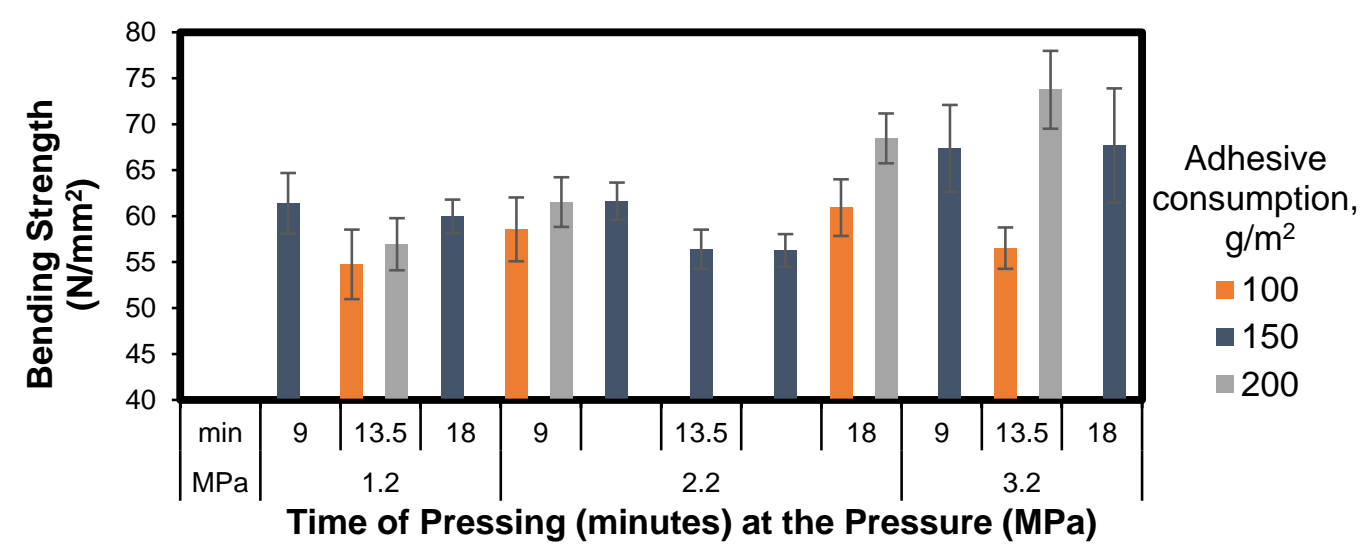

Fig. 3. Bending strength perpendicular to the grain (STDEV error bars)

The lowest static bending strength of $54.8 \mathrm{~N} / \mathrm{mm}^{2}$ was found at the following gluing parameters: pressing pressure 1.2 $\mathrm{MPa}$, holding time under pressure 13.5 minutes, and adhesive consumption $100 \mathrm{~g} / \mathrm{m}^{2}$. From three sample groups with the same pressing parameters: pressing pressure 2.2 $\mathrm{MPa}$, holding time under pressure 13.5 minutes and adhesive consumption $150 \mathrm{~g} / \mathrm{m}^{2}$, the lowest strength in static bending was $56.3 \mathrm{~N} / \mathrm{mm}^{2}$, the highest $61.6 \mathrm{~N} / \mathrm{mm}^{2}$, and the difference between these groups of samples was $5.3 \mathrm{~N} / \mathrm{mm}^{2}$. Using the t-test, differences in the variation of several unrelated sample sets were determined, and it was found that there were no significant differences between the sample sets. The observed difference between the sample averages was not conclusive enough to 
suggest that the average bending strength of these plywood bonding variants would differ significantly. The values of the modulus of elasticity of the studied samples were also similar to the bending strength - the highest value of modulus of elasticity parallel to the grain $12303 \mathrm{~N} / \mathrm{mm}^{2}$ was achieved at the following gluing parameters: pressing pressure 3.2 $\mathrm{MPa}$, holding time under pressure 13.5 minutes, and adhesive consumption $200 \mathrm{~g} / \mathrm{m}^{2}$. The lowest value of the modulus of elasticity parallel to the fibers $10064 \mathrm{~N} / \mathrm{mm}^{2}$ was at the following gluing parameters: pressing pressure $2.2 \mathrm{MPa}$, holding time under pressure 13.5 minutes, and adhesive consumption $150 \mathrm{~g} / \mathrm{m}^{2}$. Similar relationships were obtained for the modulus of elasticity perpendicular to grain. In Fig. 4 it can be convincingly observed that compression was lower at the lowest pressure than at the highest pressure.

The correlations of the indicators were obtained as follows. As the modulus of elasticity increases, the strength in static bending also increased; it was characterized by an increasing linear, close correlation and correlation coefficient $r=0.84$. There was also an increasing linear, close relationship between the density and strength of the samples in static bending, which was characterized by a correlation coefficient $r=0.83$. Other studies have shown similar relationships between the above mentioned, indicators.

\section{Pressing Degree and Final Thickness}

At the lowest pressing pressure $1.2 \mathrm{MPa}$, about $10 \%$ was pressed at the average pressing pressure $2.2 \mathrm{MPa}$ from 11 to $15 \%$, but at the highest pressing pressure it was from 16 to $22 \%$. The holding time under pressure and the consumption of adhesive had no significant effect in this case.

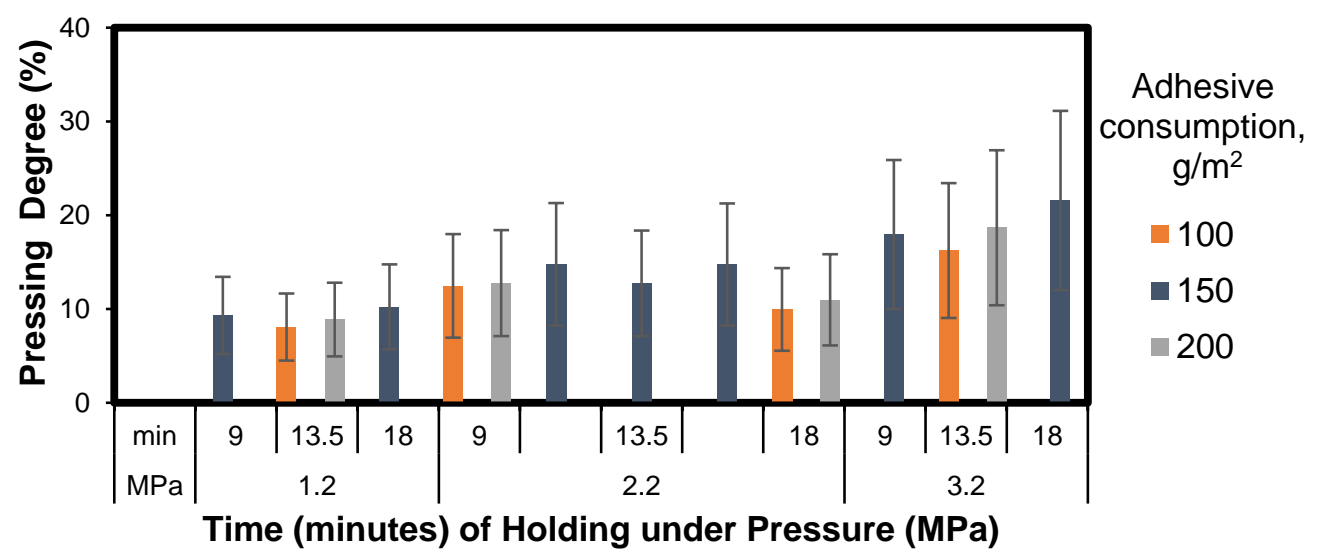

Fig. 4. Pressing degree (STDEV error bars)

The nominal, minimum, and maximum thickness parameters of $9 \mathrm{~mm}$ thick plywood were taken from the standard EN 315 (2000), JSC "Latvijas Finieris" (2020) and FFIF (2002) (Fig. 4).

Figure 5 shows the thicknesses of glued plywood with variable gluing parameters after pressing. In 5 sample groups, the thickness exceeded the permissible maximum thickness tolerance of $9 \mathrm{~mm}$ for nominal plywood, which is $9.5 \mathrm{~mm}$. The minimum thickness was $8.7 \mathrm{~mm}$ for the group of pressing samples with the highest compression pressure of 3.2 $\mathrm{MPa}$; the maximum holding time under pressure was 18 minutes, and the average adhesive consumption was $150 \mathrm{~g} / \mathrm{m}^{2}$. 

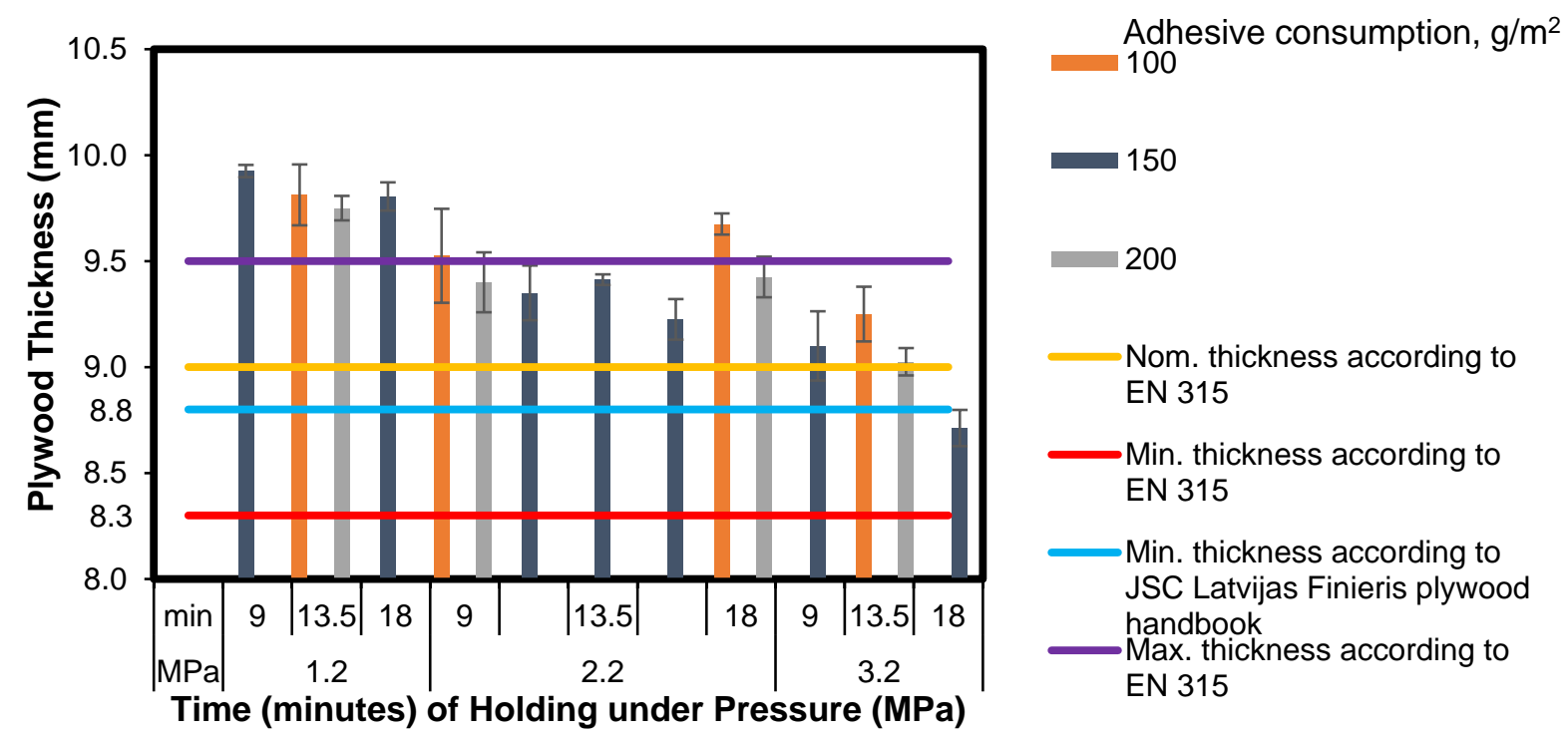

Fig. 5. Thickness of the prepared plywood groups (STDEV error bars).

\section{DISCUSSION}

\section{Bending Strength and Pressing Parameters}

The plywood pressing temperature of $135^{\circ} \mathrm{C}$ used in this research according to the production parameters and within the temperature range of 115 to $140{ }^{\circ} \mathrm{C}$, as described in the literature sources (Zeppenfeld and Grunwald 2005), was slightly lower than that used in the production $160{ }^{\circ} \mathrm{C}$ for PF resin adhesives (Thoemen et al. 2010). This also means that the energy capacity for the production of $1 \mathrm{~m}^{3}$ of plywood could be lower. However, it was higher than if UF or MF (melamine formaldehyde) resin adhesives had been used, according to the reported pressing temperature of 100 to $120{ }^{\circ} \mathrm{C}$ (Thoemen et al. 2010). Regarding the pressure, the literature indicates that for lower-density tree species, such as poplar, it would be about $1 \mathrm{MPa}$, and for even higher-density tree species it would be higher (Wang and Dai 2005; Thoemen et al. 2010). Compared to the data of the study (lower limit $1 \mathrm{MPa}$ ), it was slightly higher than indicated in the literature - for low-density tree species. In contrast, the upper pressure limit of 3.2 MPa used in the study exceeded the compression pressure of 2.5 MPa reported in other studies (Zeppenfeld and Grunwald 2005). The adhesive consumption used in the study also did not contradict the lower and average limits set by the adhesive manufacturer, as well as the limits of 160 to $230 \mathrm{~g} / \mathrm{m}^{2}$ considered in other studies (Zeppenfeld and Grunwald 2005). Taking into consideration the high proportion of adhesive for the production of $1 \mathrm{~m}^{3}$ of plywood, even if the data showed a noticeable improvement in mechanical properties, the manufacturer would not be ready to increase the amount of adhesive, since no economic justification can be found. Although the high density of birch wood does not allow for remarkable densifying of veneers, a possible solution to the reduction of the adhesive consumption until $25 \%$ and also the reduction in pressing pressure until 22\% (Bekhta and Marutzky 2007) could be a prerequisite for further research and testing with other timber species.

To investigate the factors influencing the strength of plywood, a multifactor regression analysis was performed. Initially, the following were chosen as independent factors: pressing pressure, pressing time, adhesive consumption, and plywood moisture and 
bending properties. The analysis showed that the effect of most factors on strength was statistically insignificant with a probability of up to $99 \%$. The relationship of statistically significant indicators was characterized by Eq. 2,

$$
S=6.49-6.95+0.22 B-0.5 L
$$

where $S$ is strength $\left(\mathrm{N} / \mathrm{mm}^{2}\right), M$ is moisture content $(\%), B$ is density $\left(\mathrm{kg} / \mathrm{m}^{3}\right)$ and $L$ is holding time under pressure, (minutes).

All calculated p-values of the parameters were $<0.05$, so all parameters were statistically significant and interpretations with $95 \%$ confidence. The obtained model describes the situation at the $95 \%$ confidence level, as a result of which $58 \%\left(\mathrm{R}^{2}=0.58\right)$ of the changes in plywood thickness could be explained by a 3-factor (moisture, density, holding time under pressure) regression model. Since the model had a $\mathrm{p}$-value $=0.000$ $<0.05$, as well as $\mathrm{F}$ test values $\left(\mathrm{F}_{\text {actual }}=67.3>\mathrm{F}_{\text {crit }}=2.67\right)$, the model was statistically significant and applicable. Thus, by reducing the moisture content of plywood by $1 \%$ point, without changing other indicators, the strength increased by $6.95 \mathrm{~N} / \mathrm{mm}^{2}$ (the increase was within the range from 3.9 to $10 \mathrm{~N} / \mathrm{mm}^{2}$ ), with a probability of $58 \%$. By increasing the holding time by one minute without changing other factors, the strength of the material decreased by $0.5 \mathrm{~N} / \mathrm{mm}^{2}$ (reduction ranges from 0.95 to $0.06 \mathrm{~N} / \mathrm{mm}^{2}$ ), with a probability of $58 \%$. On the other hand, by increasing the density of the material by 1 unit, without changing other factors, the strength of the material increased by $0.22 \mathrm{~N} / \mathrm{mm}^{2}$ (increasing from 0.19 to $0.26 \mathrm{~N} / \mathrm{mm}^{2}$ ) with confidence of $58 \%$. This means that the highest possible strength can be obtained by choosing a denser and drier raw material and pressing it for as short a time as possible (with a probability of 58\%). When using the conclusions of the study, it should be taken into account that the selected values of factors (time, humidity, density) must not differ significantly from those used in the analysis, for example, holding time $(\mathrm{t})$ as follows $9.5 \pm 0.01 \leq \mathrm{t} \leq 18 \pm 0.01$.

To find out how to change the value of one of the factors to maintain the strength of the material by increasing the value of another factor by 1 unit, the marginal norm of resource substitutability was used and the moisture substitutability norm of the plywood strength model was obtained, depending on time (Eq. 3):

$$
\Delta M_{L}=-\frac{S_{L}^{\prime}}{S^{\prime}{ }_{M}}=-\frac{-0.5}{-6.95}=-0.72
$$

Thus, the holding time under pressure was increased by 1 minute in order to keep the planned strength of the resulting plywood constant, and the moisture content of the plywood had to be reduced by 0.72 percentage points.

To increase the strength of plywood by pressing at different pressing parameters additional substances should be added to the adhesive, as Muñoz and Moya have done in their study, by adding 0.75 parts by weight of the nanoclay product to the adhesive ureaformaldehyde resin (Muñoz and Moya 2018). This would make it possible to use a cheaper adhesive compared to phenol formaldehyde resins, although further research is required to determine the optimal pressing technological parameters of the modified adhesive used.

\section{Pressing Degree and Final Thickness}

The minimum thickness of $8.7 \mathrm{~mm}$ for the group of pressing samples with the highest compression pressure of 3.2 $\mathrm{MPa}$, the maximum holding time under pressure of 18 minutes, and the average adhesive consumption of $150 \mathrm{~g} / \mathrm{m}^{2}$, in compliance with the requirements of standard EN 315 (2000), however slightly did not meet the requirements 
of the JSC "Latvijas Finieris" and FFIF (2002) handbooks. All variants with the lowest pressing pressure of $1.2 \mathrm{MPa}$ did not fulfil the dimensional requirements for the maximum thickness tolerance. The results needed to fall within the maximum dimensional thickness tolerance, with their thicknesses range from 9.8 to $9.9 \mathrm{~mm}$. Increasing the holding time under pressure, the thickness of the plywood was reduced. The maximum limit was also exceeded by $0.2 \mathrm{~mm}$ by the pressing variant with an average pressing pressure of $2.2 \mathrm{MPa}$, the highest holding time under pressure of 18 minutes, and the lowest adhesive consumption of $100 \mathrm{~g} / \mathrm{m}^{2}$.

When studying the relations between the pressing pressure, the amount of adhesive and the time under pressure, the semi-logarithmic model was the most suitable (Eq. 4),

$$
h=11.46155-0.17359 \ln (t)-0.39125 P-0.00418 L
$$

where $h$ is thickness (mm), $t$ is holding time under pressure (minutes), $P$ is pressure (MPa), and $L$ is adhesive consumption $\left(\mathrm{g} / \mathrm{m}^{2}\right)$.

All calculated p-values were $<0.01$, so all the parameters were statistically significant and interpretable. The specific model describes the situation at the $95 \%$ confidence level, so $76 \%\left(\mathrm{R}^{2}=0.76\right)$ of the changes in plywood thickness could be explained by the 3-factor regression model. No autocorrelation or heteroscedasticity problems were found. Although a statistically significant three-factor model has been obtained for predicting plywood thickness, it is recommended not to adjust the adhesive consumption, as increasing it will minimally change the expected result. Increasing the applied pressure by $1 \mathrm{MPa}$ will reduce the thickness of the plywood by $0.39 \mathrm{~mm}$, without changing other factors. Assessing the interval of change, this reduction could be within the range of 0.35 units to 0.42 units with $95 \%$ confidence, without changing the other indicators. When estimating the mean thickness with $95 \%$ confidence, it is $9.53 \pm 0.6 \mathrm{~mm}$. No autocorrelation or heteroscedasticity problem was found.

Examining the literature data and analyzing plywood hot pressing parameters used in practice, the following conclusions can be arrived at: gluing 7- layer $(9 \mathrm{~mm})$ thick birch plywood, in order not to exceed the upper limit of the prepared plywood thickness $(9.5$ $\mathrm{mm}$ ), the pressing pressure should be at least $1.7 \mathrm{MPa}$. In this case the average adhesive consumption should be $200 \mathrm{~g} / \mathrm{m}^{2}$ and the holding time under pressure should be 15 minutes, which will allow one to obtain similar predictable strength as it currently varies.

The exact density of each veneer has not been determined in this study and, as it is well known, the density has a direct effect on the density of the final material - plywood, and thereby on its mechanical properties. It follows that further studies should be focused on whether and how veneer density affects the mechanical properties of plywood at the optimal pressing parameters determined in this study.

\section{CONCLUSIONS}

1. The highest strength in static bending, both parallel and perpendicular to the grain, was obtained with the following gluing parameters: the highest pressing pressure 3.2 $\mathrm{MPa}$, the lowest holding time under pressure 9 minutes and the average adhesive consumption of $150 \mathrm{~g} / \mathrm{m}^{2}$. 
2. After the experiment of static bending parallel to the grain, calculating the optimal pressing parameters, it was concluded that the pressing pressure must be $1.8 \mathrm{MPa}$; the holding time under pressure must be 12 minutes and 36 seconds, and the adhesive consumption must be $301 \mathrm{~g} / \mathrm{m}^{2}$.

3. Concluding that the obtained optimal adhesive consumption is higher than the upper limit of the variation, which was $200 \mathrm{~g} / \mathrm{m}^{2}$, the optimal values were recalculated, assuming that the optimal adhesive consumption is in the upper limit of the variation $200 \mathrm{~g} / \mathrm{m}^{2}$, the optimal values of the binding factors shall be as follows: pressing pressure $1.67 \mathrm{MPa}$ and holding time under pressure 14 minutes and 48 seconds.

4. When pressing at a minimum pressing pressure of $1.5 \mathrm{MPa}$, all variants exceeded the upper limit of $8.9 \mathrm{~mm}$ for $9 \mathrm{~mm}$ thick plywood.

5. Using the mathematically calculated pressing parameters - pressing pressure $1.7 \mathrm{MPa}$, holding time under pressure 14 minutes $48 \mathrm{~s}$, adhesive consumption $200 \mathrm{~g} / \mathrm{m}^{2}$, the predicted ultimate strength in the static bending would be $\sim 97 \mathrm{~N} / \mathrm{mm}^{2}$, which is average compared to the experimental results.

6. Mathematically creating a 3-factor model for predicting plywood thickness, it is concluded that the resulting consumption of adhesive and time under pressure have a minimal effect on the results. On the other hand, increasing the applied pressure by 1 $\mathrm{MPa}$ will reduce the thickness of the plywood by $0.39 \mathrm{~mm}$.

\section{ACKNOWLEDGMENTS}

This research was carried out within the project G2 "Prediction of Properties of the Environment Friendly Engineered Wood Composites" (No. 3.2-10/2) co-financed by the program "Implementation of fundamental research at Latvia University of Life Sciences and Technologies"

\section{REFERENCES CITED}

Baldwin, R. F. (2016). Plywood and Veneer-Based Products, The Donnell Group, Montgomery, AL, USA.

Bekhta, P., and Marutzky, R. (2007). "Reduction of glue consumption in the plywood production by using previously compressed veneer," Holz Roh Werkst 65, 87-88. DOI: $10.1007 / \mathrm{s} 00107-006-0142-8$

EN 310 (1993). "Wood-based panels. Determination of modulus of elasticity in bending and of bending strength," European Committee for Standardization, Brussels, Belgium.

EN 314-1 (2004). "Plywood. Bonding quality. Test methods," European Committee for Standardization, Brussels, Belgium.

EN 314-2 (1993). "Plywood. Bonding quality. Requirements," European Committee for Standardization, Brussels, Belgium.

EN 315 (2000). "Plywood. Tolerances for dimensions," European Committee for Standardization, Brussels, Belgium.

Finnish Forest Industries Federation (FFIF) (2002). Handbook of Finnish Plywood, Lahti, 
Finland.

Hogger, E. M., Hendrikus, W., Van Herwijnen G., Moser J., Kantner, W., and Konnerth, J. (2018). "Cold tack of urea formaldehyde resins as an important factor in plywood production," European Journal of Wood and Wood Products 76(5), 1391-1398. DOI: 10.1007/s00107-018-1332-x

Horizons - Vision 2030 for the European Forest-based Sector (2013). Renewed FTP Vision 2030. Forest-based Sector Technology Platform (FTP), Brussels, Belgium. JSC Latvijas Finieris (2020). Plywood Handbook, Riga, Latvia.

Lipinskis, I., and Spulle, U. (2011). "Research on mechanical properties of birch plywood with special veneer lay-up schemes," Drewno 54(185), 109-118.

Muñoz, F., and Moya, R. (2018). "Effect of nanoclay-treated UF resin on the physical and mechanical properties of plywood manufactured with wood from tropical fast growth plantations," Maderas Ciencia \& Tecnología. 20(1), 11-24. DOI: 10.4067/S0718-221X2018005001202

Shupe, T. F., Hse, C. Y., Grozdits, G. A., and Choong, E. T. (1997). "Veneer lay up on some mechanical properties of loblolly pine plywood," Forest Products Journal 47(10), 101-106.

Spulle, U. (2003). Bending Strength and Modulus of Elasticity of the Plywood, Master's Thesis, Latvijas Lauksaimniecības universitāte, Jelgava, Latvia.

Thoemen, H., Irle, M., and Sernek, M. (2010). Wood Based Panels. Introduction for Specialists, COST Action, Brunel University Press, London.

Volynsky, V. N. (2008). Technology of Glued Materials, Профикс, St. Petersburg, Russia.

Wang, B. J., and Dai, C. (2005). "Hot-pressing stress graded aspen veneer for laminated veneer lumber (LVL)," Holzforschung 59(1), 10-17.

Zeppenfeld, G., and Grunwald, D. (2005). Klebstoffe in der Holz- und Möbelindustrie; 2. Überarbeitete und Erweiterte Auflage. KG, Leinfelden-Echterdingen, DRW-Verlag Weinbrenner GmbH \& Co.

Article submitted: August 2, 2021; Peer review completed: September 5, 2021; Revised version received: September 14, 2021; Accepted: September 15, 2021; Published:

September 24, 2021.

DOI: $10.15376 /$ biores.16.4.7550-7561 